\title{
Effect of Monthly, High-Dose, Long-Term Vitamin D on Lung Function: A Randomized Controlled Trial
}

\author{
John D. Sluyter ${ }^{1, *}$, Carlos A. Camargo, Jr. ${ }^{2}$, Debbie Waayer ${ }^{1}$, Carlene M. M. Lawes ${ }^{1}$, Les Toop ${ }^{3}$, \\ Kay-Tee Khaw ${ }^{4}$ and Robert Scragg ${ }^{1}$ \\ 1 School of Population Health, University of Auckland, Auckland 1072, New Zealand; \\ d.waayer@auckland.ac.nz (D.W.); carlene.lawes@waitematadhb.govt.nz (C.M.M.L.); \\ r.scragg@auckland.ac.nz (R.S.) \\ 2 Department of Emergency Medicine, Massachusetts General Hospital, Harvard Medical School, \\ Boston, MA 02114, USA; ccamargo@partners.org \\ 3 Department of General Practice, University of Otago, Christchurch 8011, New Zealand; les.toop@otago.ac.nz \\ 4 Department of Public Health and Primary Care, University of Cambridge, Cambridge CB3 OEQ, UK; \\ kk101@medschl.cam.ac.uk \\ * Correspondence: j.sluyter@auckland.ac.nz; Tel.: +64-9-923-6702
}

Received: 31 October 2017; Accepted: 8 December 2017; Published: 13 December 2017

\begin{abstract}
Although observational studies suggest positive vitamin D-lung function associations, randomized trials are inconsistent. We examined effects of vitamin D supplementation on lung function. We recruited 442 adults (50-84 years, 58\% male) into a randomized, double-blinded, placebo-controlled trial. Participants received, for 1.1 years (median; range $=0.9-1.5$ years), either (1) vitamin $\mathrm{D}_{3} 200,000 \mathrm{IU}$, followed by monthly 100,000 IU doses $(n=226)$; or (2) placebo monthly $(n=216)$. At baseline and follow-up, spirometry yielded forced expiratory volume in $1 \mathrm{~s}$ (FEV1; primary outcome). Mean (standard deviation) 25-hydroxyvitamin D increased from 61 (24) nmol/L at baseline to 119 (45) $\mathrm{nmol} / \mathrm{L}$ at follow-up in the vitamin $\mathrm{D}$ group, but was unchanged in the placebo group. There were no significant lung function improvements (vitamin D versus placebo) in the total sample, vitamin D-deficient participants or asthma/chronic obstructive pulmonary disease (COPD) participants. However, among ever-smokers $(n=217)$, the mean $(95 \%$ confidence interval) FEV1 increase in the vitamin D versus placebo was $57(4,109) \mathrm{mL}(p=0.03)$. FEV1 increases were larger among vitamin D-deficient ever-smokers $(n=54): 122(8,236) \mathrm{mL}(p=0.04)$. FEV1 improvements were largest among ever-smokers with asthma/COPD $(n=60): 160(53,268) \mathrm{mL}(p=0.004)$. Thus, vitamin D supplementation did not improve lung function among everyone, but benefited ever-smokers, especially those with vitamin D deficiency or asthma/COPD.
\end{abstract}

Keywords: vitamin D; lung function; forced expiratory volume in $1 \mathrm{~s}$; spirometry; randomized controlled trial

\section{Introduction}

Population-based observational studies have found that low serum 25-hyroxyvitamin D $(25(\mathrm{OH}) \mathrm{D})$ concentration is associated with poor lung function [1,2]. However, the observational design prevents one from knowing whether these relationships are causal, or whether they could be reversed by increasing $25(\mathrm{OH}) \mathrm{D}$. To investigate the causality and reversibility of these associations, randomized controlled trials (RCTs) of vitamin D supplementation are required.

A limited number of RCTs have investigated the effect of vitamin D supplementation on lung function in adults [3-10]. However, vitamin D efficacy remains unclear, due to the conflicting findings of these trials: some reported beneficial changes $[7,8,11,12]$, others found no effects $[3,4,10]$, and another reported mixed results [9]. Most of these studies had relatively small sample sizes 
( $n \leq 130)$ [3,4,7-9] and short follow-up periods ( $<1$ year), which limited their ability to assess long-term efficacy $[3,4,6-9]$. Nearly all of these studies were restricted to patients with respiratory conditions such as asthma [6,8-10] or chronic obstructive pulmonary disease (COPD) $[4,5,7]$. However, vitamin D trials should include other groups of people, too, in order to study the role of vitamin D supplementation on lung health in general [13]. Trials should also investigate vitamin D-deficient people and smokers, as vitamin D supplementation could potentially be more effective in these people. This is because non-linear relationships between 25(OH)D and health outcomes suggest that adverse effects associated with low vitamin D status are greatest in vitamin D-deficient people [14-16], while observational studies suggest that the relationship between $25(\mathrm{OH}) \mathrm{D}$ and lung function could be stronger in smokers than in non-smokers [1,17-19].

Given the above knowledge gaps, we used an RCT design to investigate the effect of long-term ( $\geq 1$ year on average), high-dose vitamin D supplementation on lung function in a population-based sample of $>400$ adults. We performed pre-specified subgroup analyses among participants who had vitamin D deficiency or asthma/COPD, or were smokers.

\section{Material and Methods}

\subsection{Participants}

The present study involved a pre-specified analysis of a sub-sample of participants in the ViDA (Vitamin D Assessment) study, who underwent follow-up measurements for 1 year. The ViDA study was a randomized, double-blinded, placebo-controlled trial of the effect of vitamin D supplementation on health outcomes, with cardiovascular disease as the primary endpoint. Participants were identified mostly from patient lists of family practices, and the remainder from ethnic minority community groups, and we recruited them to our study by post and subsequent follow-up telephone calls. Inclusion criteria were men and women from these family practice registers and community groups, aged 50-84 years and resident in Auckland at recruitment. Exclusion criteria included: (1) diagnosis of a terminal illness and/or in hospice care; (2) intending to leave New Zealand during the follow-up period; (3) taking vitamin D supplements (including cod liver oil) of $>600$ IU daily if aged 50-70 years or $>800$ IU daily if aged 71-84 years; (4) history of renal stones, hypercalcemia, or medical conditions that can cause hypercalcemia; and (5) baseline serum calcium $>2.50 \mathrm{mmol} / \mathrm{L}$. Screening and baseline measurements took place at the School of Population Health (University of Auckland) between 2011 and 2012, with 5110 being randomized using computer generation to receive either vitamin D or placebo. Random assignment to one of the two treatment groups was made with random block sizes of 8,10 or 12 , within ethnic and 5-year age groups. As each participant became eligible for randomization, the next sequential treatment within their ethnic and age stratum was allocated. The randomization process was supervised by the study biostatistician to ensure that participants and staff who collected the data were blinded to allocation. Ethics approval was provided by the New Zealand Multi-region Ethics Committee (MEC/09/08/082). Written, informed consent was obtained from each participant. This study was registered with the Australian New Zealand Clinical Trials Registry (http:/ / www.anzctr.org.au; ACTRN12611000402943). Full study-design details have been published elsewhere [20]. The results are reported according to Consolidated Standards of Reporting Trials (CONSORT) guidelines [21].

\subsection{Vitamin D Intervention}

Vitamin $\mathrm{D}_{3}(100,000 \mathrm{IU}(2.5 \mathrm{mg}))$ or placebo softgel oral capsules, sourced from Tishcon Corporation (Westbury, NY, USA), were mailed to participants' homes. Two capsules were sent in the first mail-out after randomization (that is, a 200,000 IU bolus, or placebo, at the start of the intervention period), followed by a monthly 100,000 IU (daily dose equivalent $~ 3300$ IU/day) capsule of vitamin $\mathrm{D}_{3}$ (or placebo) throughout the remainder of the trial. To achieve masking, the vitamin $\mathrm{D}$ and placebo capsules were identical in appearance. 


\subsection{Non-Lung Function Measures}

All measurements were carried out by trained staff using a standardized protocol. Questionnaires administered by interviewers were used to collect data on age, sex, ethnicity (defined by self-identification), smoking, sun exposure, history of asthma (including the Asthma Control Test (ACT) [22]), use of vitamin D supplements, and medications for asthma, chronic bronchitis or emphysema. An ACT score of $\geq 20$ denoted well-controlled asthma [23]. An ever-smoker was defined as a current or former smoker. Participants were also asked the number of years since quitting (for ex-smokers) and the number of cigarettes smoked per day (for current smokers). Lung-related medications were determined from the questionnaire (described above) and national medicine-dispensing database. Without shoes and in light clothing, height $( \pm 0.1 \mathrm{~cm})$ was measured with a stadiometer, and weight $( \pm 0.1 \mathrm{~kg})$ with digital scales. Body mass index was calculated as weight $(\mathrm{kg}) /$ height $\left(\mathrm{m}^{2}\right)$.

Blood samples were collected at baseline, and at 6 and 12 months of follow-up to measure calcium for hypercalcemia (corrected calcium $>10.4 \mathrm{mg} / \mathrm{dL}$ ). Remaining plasma aliquots were stored frozen at $-80{ }^{\circ} \mathrm{C}$. Serum $25(\mathrm{OH}) \mathrm{D}$ (combining $\mathrm{D}_{2}$ and $\mathrm{D}_{3}$ ) concentration was measured in these aliquots (baseline and follow-up samples were measured in the same batch for each participant) by liquid chromatography-tandem mass spectrometry (ABSciex API 4000, Framingham, MA, USA) at a laboratory participating in the Vitamin D External Quality Assessment Scheme (DEQAS) program (www.deqas.org).

\subsection{Lung Function Measures}

Lung function was assessed with a KoKo Trek spirometer (nSpire Health, Longmont, CO, USA) in a seated position. All published recommendations for spirometry measurement [24] were adhered to, except attaining three acceptable measures from a maximum of 8 efforts. In our study, which was ancillary to a much larger trial of 5110 participants who all had the same standard baseline assessment, only three efforts were performed due to time constraints and to avoid exhaustion in elderly participants. Participants were educated about the spirometric technique verbally and via demonstration, and while watching a clock on the computer screen were encouraged to inhale and exhale as maximally and forcibly as possible for at least $6 \mathrm{~s}$. Maximum values of forced expiratory volume in $1 \mathrm{~s}$ (FEV1; in $\mathrm{mL}$ ), forced vital capacity (FVC; in mL) and FEV1 as a percentage of FVC (FEV1/FVC) from three efforts (not necessarily from the same effort) were used for analyses. FEV1 was the primary outcome [12], with FVC and FEV1/FVC as secondary outcomes. The quality of the spirometry measurements was graded (from A to F) and classified into two groups: measurements with grades A or B (representing higher-quality measurements) and those with grades $C$ to $F$ (representing lower-quality measurements). A and B grades included participants with acceptable spirometry, with at least two measurements out of three within $150 \mathrm{~mL}$ of one another and exhalation time of more than $6 \mathrm{~s} \mathrm{[24].}$

A FEV1/FVC value of $<70 \%$ was used to define COPD, as recommended by the 2017 Global Initiative on Obstructive Lung Disease (GOLD) classification of COPD [25]. COPD severity was graded using GOLD stages, which are based on percentage of predicted FEV1 values (where predicted FEV1 values were calculated from published equations [26]): stage 1 (mild): $\geq 80 \%$; stage 2 (moderate): 50-79\%; stage 3 (severe): $30-49 \%$; and stage 4 (very severe): $<30 \%$ [25]. These equations were also used to calculate spirometric $z$-scores [26].

\subsection{Statistical Analysis}

Data were analysed using SAS version 9.3 (SAS Institute, Cary, NC, USA). On an intention-to-treat basis, PROC MIXED general linear mixed models were used to assess the effect of vitamin D supplementation (exposure) on the outcomes, 25(OH)D and lung function parameters (adjusted for age, sex, ethnicity and height), with repeated time incorporated using an unstructured correlation structure. This analysis method handles missing data by fitting a statistical model over all available observations without introducing bias. Potential three-way interactions between spirometry grade 
acceptability (grades A or B versus other grades), treatment group and time were examined, but as they were not statistically significant, we did not report results by spirometry grade acceptability.

Deseasonalised (season-adjusted) baseline 25(OH)D levels were calculated for each participant from the mid-point between the estimated maximum and minimum $25(\mathrm{OH}) \mathrm{D}$ levels over a calendar year, from their individual measured baseline $25(\mathrm{OH}) \mathrm{D}$ and date of blood collection, using a sinusoidal model with parameters derived from baseline values for all participants in the main ViDA study [27]. Vitamin D deficiency was defined as having a deseasonalised 25(OH)D of $<50 \mathrm{nmol} / \mathrm{L}$ [27].

Aside from performing analysis among all eligible participants (total sample), we decided a priori to conduct subgroup analyses among participants with baseline vitamin D deficiency, asthma/COPD, and a smoking history (ever-smokers), given the abovementioned rationale for these. These analyses included combinations of these subgroups to explore potentially cumulative effects. Due to small sample sizes, especially in these mixed-subgroup analyses, we combined asthma cases with COPD cases and ex-smokers with current smokers. In further analyses, we examined three-way interactions-between smoking status (ever-smoker or not), treatment group, and time- to test whether the effects of vitamin D were different in ever-smokers than in never-smokers.

The ViDA study was originally powered to detect a clinically relevant reduction in cardiovascular events (primary outcome), as described elsewhere [20]. For the current sub-study, with a standard deviation of FEV1 change of $180 \mathrm{~mL}, 80 \%$ power and at the $5 \%$ significance level (two-tailed), the minimum detectable differences in FEV1 were about $48 \mathrm{~mL}$ in the total sample, $89 \mathrm{~mL}$ in all vitamin D-deficient people, $96 \mathrm{~mL}$ in everyone with asthma/COPD, and $69 \mathrm{~mL}$ in all ever-smokers.

Correlations between changes in observed $25(\mathrm{OH}) \mathrm{D}$ and changes in lung function parameters were summarized with Pearson correlation coefficients $(r)$. Robust estimates (95\% confidence intervals) of these correlation coefficients were calculated using 1000 bootstrap samples. $p$-values were not corrected to account for multiple hypothesis tests, as we did not want to miss any potentially important findings [28]. A two-sided $p<0.05$ was considered statistically significant.

\section{Results}

The study flowchart is shown in Figure 1. From the 5110 participants randomized in the main ViDA study, $517(10 \%)$ were randomly selected and invited to partake in the current sub-study. Of these, 74 declined and 1 withdrew consent (data analysis prohibited), and were thus not included in subsequent analyses. Out of the remaining 442, a complete set of both baseline and 1-year follow-up measurements was available in 366 participants ( $83 \%$ ). The 76 participants with missing data comprised 49 who did not attend the follow-up interview (could not attend, uncontactable or moved overseas) and 27 who had unobtainable spirometry data (could not obtain a reading). Per intention-to-treat, all 442 people were included in the total-sample analysis. The proportion of the total sample with missing follow-up data did not differ across the two treatment groups ( $p=0.96, \chi^{2}$ test). Further, baseline lung function of those with missing follow-up data did not differ from those without missing follow-up data ( $p$-values ranging from 0.47 to 0.57 ; analysis of variance.)

Of the total sample, 226 received vitamin D and 216 received the placebo. Table 1 shows the baseline characteristics of these participants by treatment group. The follow-up period (randomization-follow-up) averaged 1.1 years (mean and median) and ranged from 0.9 to 1.5 years. The mean age was 65 years (range: $50-84$ years), $58 \%$ were male and just over three-quarters were of European/Other ethnicity (with $96 \%$ having European ancestry). Fourteen percent had asthma (77\% well-controlled-ATS score $\geq 20$ ) and $17 \%$ had COPD (mostly mild or moderate-GOLD stages 1 and 2). Nearly $30 \%$ had a deseasonalised $25(\mathrm{OH}) \mathrm{D}$ of $<50 \mathrm{nmol} / \mathrm{L}$ (vitamin D deficiency). Almost one-half $(49 \%)$ had smoked ( $82 \%$ of whom were ex-smokers). Supplementary analyses (not tabulated) showed that ex-smokers had quit a median of 30 years earlier (interquartile range: 13 to 40 years), and the median number of cigarettes smoked per day among current smokers was approximately just under 10 ( $54 \%$ smoked $\leq 10$ per day). Further supplementary analyses showed that the proportion 
of participants with spirometry grades A or B were similar in the vitamin D (30\%) and placebo $(28 \%)$ groups.

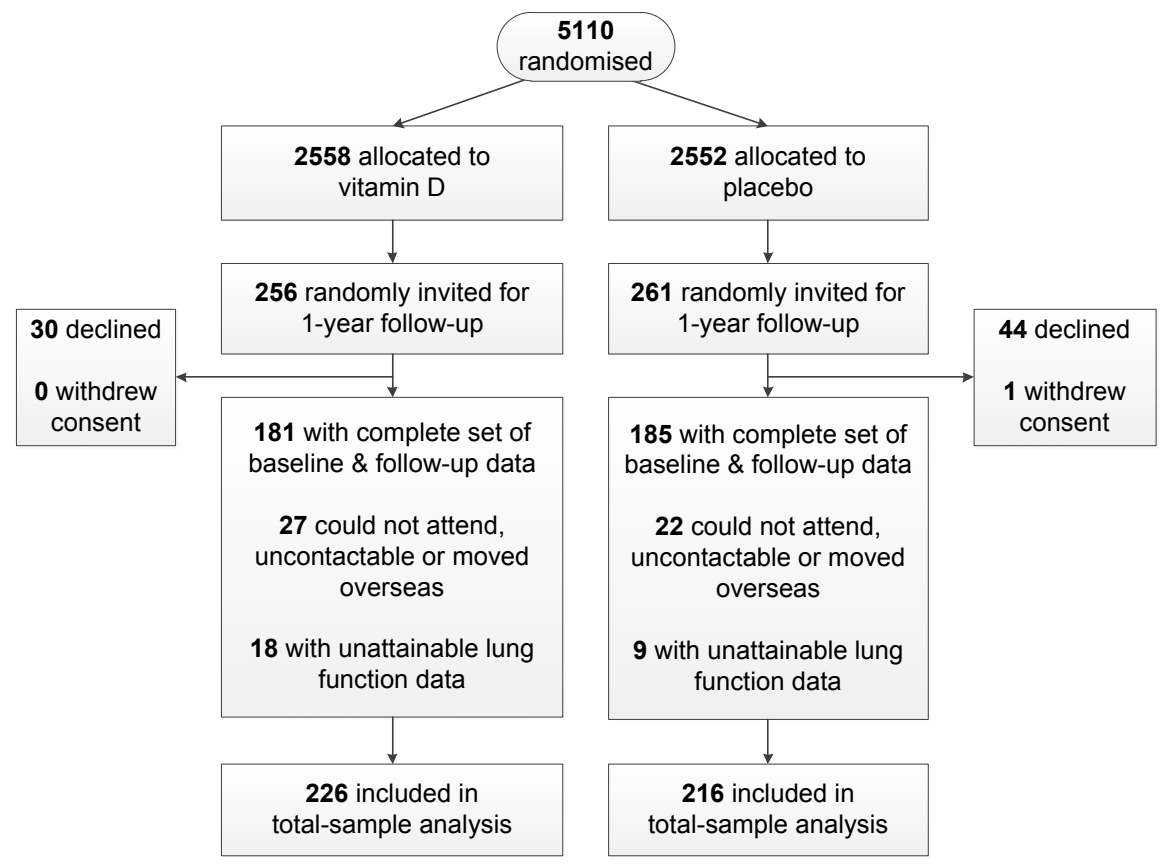

Figure 1. Flowchart showing the number of randomized participants who were excluded and those with a complete set of both baseline and 1-year follow-up measurements.

Table 1. Baseline characteristics of all participants across treatment groups.

\begin{tabular}{|c|c|c|}
\hline Variable & Vitamin D & Placebo \\
\hline$n$ & 226 & 216 \\
\hline Days from randomization to follow-up ${ }^{1}$ & $401 \pm 29$ & $402 \pm 30$ \\
\hline Age (years) ${ }^{1}$ & $64.6 \pm 8.4$ & $65.4 \pm 9.0$ \\
\hline Male sex $(n(\%))$ & $140(62)$ & $117(54)$ \\
\hline \multicolumn{3}{|l|}{ Ethnicity } \\
\hline European/Other $(n(\%))$ & $172(76)$ & $169(78)$ \\
\hline Maori $(n(\%))$ & $15(7)$ & $13(6)$ \\
\hline Pacific $(n(\%))$ & $22(10)$ & $16(7)$ \\
\hline South Asian $(n(\%))$ & $17(8)$ & $18(8)$ \\
\hline Asthma $(n(\%))$ & $28(12)$ & $36(17)$ \\
\hline ACT score, median $\pm \mathrm{IQR}$ & $23.5 \pm 4.5$ & $21.5 \pm 5.5$ \\
\hline $\operatorname{COPD}(n(\%))$ & $40(18)$ & $37(17)$ \\
\hline GOLD stage $1(n(\%))$ & $15(7)$ & $14(6)$ \\
\hline GOLD stage $2(n(\%))$ & $19(8)$ & $18(8)$ \\
\hline GOLD stage $3(n(\%))$ & $4(2)$ & $2(1)$ \\
\hline GOLD stage $4(n(\%))$ & $2(1)$ & $3(1)$ \\
\hline Body mass index $\left(\mathrm{kg} / \mathrm{m}^{2}\right)^{1}$ & $28.6 \pm 5.2$ & $28.5 \pm 4.9$ \\
\hline \multicolumn{3}{|l|}{ 25-hydroxyvitamin D } \\
\hline Observed ${ }^{1}$ & $61.5 \pm 24.4$ & $61.4 \pm 23.7$ \\
\hline Deseasonalised $^{1}$ & $66.0 \pm 23.7$ & $65.5 \pm 23.3$ \\
\hline Deseasonalised < $50 \mathrm{nmol} / \mathrm{L}(n(\%))$ & $61(27)$ & $68(31)$ \\
\hline Lung function medication $(n(\%))$ & $21(9)$ & $27(13)$ \\
\hline On vitamin D supplements at baseline $(n(\%))$ & $27(12)$ & $22(10)$ \\
\hline
\end{tabular}


Table 1. Cont.

\begin{tabular}{ccc}
\hline Variable & Vitamin D & Placebo \\
\hline Smoking & & \\
\hline Never-smoker $(n(\%))$ & $122(54)$ & $103(48)$ \\
Ex-smoker $(n(\%))$ & $83(37)$ & $95(44)$ \\
Current smoker $(n(\%))$ & $21(9)$ & $18(8)$ \\
\hline Sun exposure (hours/day) & & \\
\hline$<1(n(\%))$ & $34(15)$ & $29(13)$ \\
$1-2(n(\%))$ & $113(50)$ & $118(55)$ \\
$>2(n(\%))$ & $79(35)$ & $69(32)$ \\
\hline
\end{tabular}

Abbreviations: ACT = Asthma Control Test; COPD = chronic obstructive pulmonary disease; GOLD = 2017 Global Initiative on Obstructive Lung Disease classification; IQR = interquartile range. ${ }^{1}$ Values are mean \pm standard deviation.

The deseasonalised 25(OH)D concentrations at baseline and follow-up visits by treatment group are illustrated in Figure 2. In the total sample, the change (95\% confidence interval) from baseline in the vitamin D group compared to placebo at 6 and 12 months follow-up, respectively, was $+51(45,58)$ and $+57(51,64) \mathrm{nmol} / \mathrm{L}(p<0.001)$. No cases of hypercalcemia were detected.
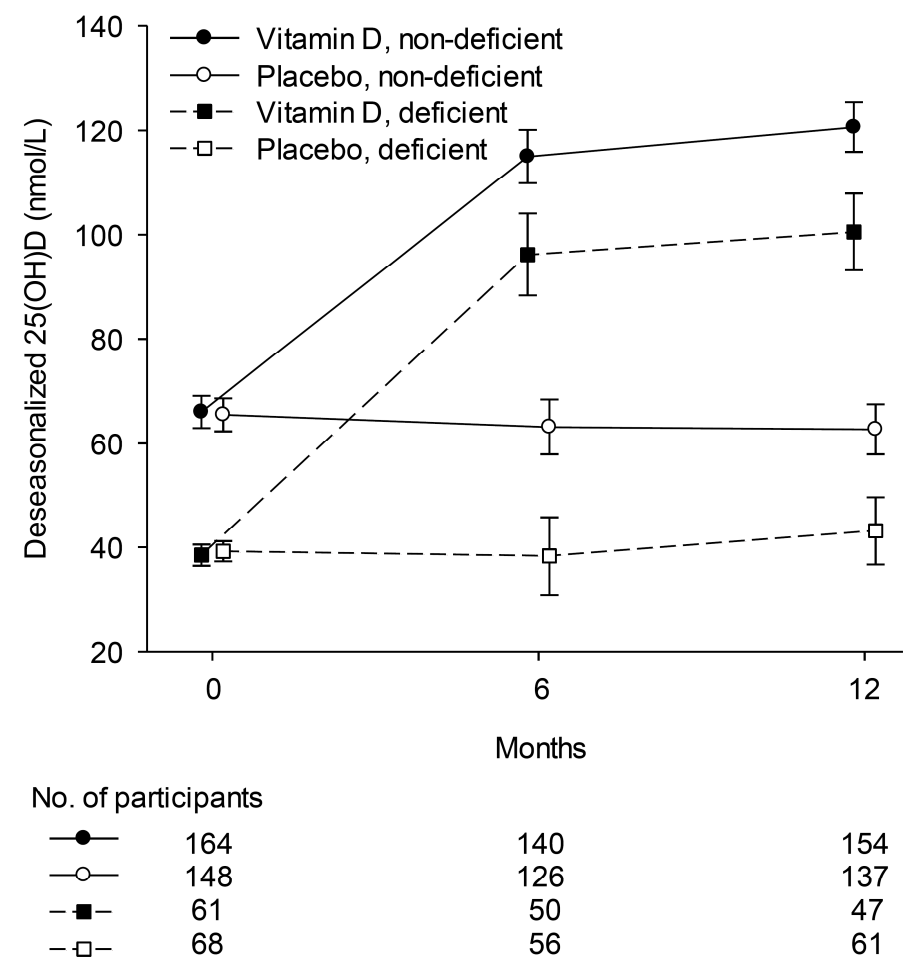

Figure 2. Line graph showing deseasonalised $25(\mathrm{OH}) \mathrm{D}$ concentration (mean $\pm 95 \%$ confidence intervals; in nmol/L) at baseline and follow-up (6 and 12 months) in the vitamin D and placebo groups, for non-vitamin D-deficient and vitamin D-deficient people. Baseline 25(OH)D was missing for 1 person (vitamin D group).

FEV1 at baseline and follow-up by intervention group is shown in Table 2. All effects were in the positive direction for the vitamin D supplemented group compared to placebo. The effects were non-significant in the total $(n=442)$, vitamin D-deficient $(n=130)$ and asthma/COPD $(n=113)$ samples. This was true, too, among participants with both asthma/COPD and vitamin D-deficiency, despite the effect being large $(109 \mathrm{~mL})$ and borderline significant $(p=0.08)$. Conversely, among all ever-smokers, FEV1 significantly increased in the vitamin D group with respect to placebo $(p=0.03)$, 
with a mean $(95 \%$ confidence interval) change of $57(4,109) \mathrm{mL}$. This effect more than doubled when restricted to ever-smokers who also had vitamin D deficiency ( $\beta=122 \mathrm{~mL}, p=0.04$ ) or asthma/COPD ( $\beta=160 \mathrm{~mL}, p=0.004)$. Similar patterns were observed when we modelled FEV1 as a $z$-score, with net (placebo-controlled) vitamin D effects of $0.13(0.01,0.24 ; p=0.03)$ and $0.35(0.11,0.59 ; p=0.005)$ $z$-scores among all ever-smokers and ever-smokers with asthma/COPD, respectively (Table S1).

When these analyses were repeated with FVC as the response variable (Table 3), all effects were smaller (compared to FEV1 effects). The effect of vitamin D compared to placebo was minimal and non-significant $(p>0.05)$ in the total sample. Across subgroup samples, the effect was larger (in nearly all cases) and consistently in the positive direction, although still not statistically significant. Similar patterns were observed with FVC as a $z$-score (Table S2).

When these analyses were repeated with FEV1/FVC as the dependent variable, all effects (vitamin D compared to placebo) were in the positive direction (Table 4). The effect among all ever-smokers was $1.1 \%(p=0.05)$ and almost tripled when confined to ever-smokers who also had asthma/COPD ( $\beta=3.0 \%, p=0.01$ ). Similarly, all FEV1/FVC $z$-score effects were in the positive direction, with the largest being among ever-smokers with asthma/COPD $(\beta=0.37, p=0.01$; Table S3).

Further analysis showed that vitamin D (with respect to placebo) significantly improved FEV1 more in ever-smokers than in never-smokers ( $p=0.02$ for three-way interaction between smoking, treatment group, and time). We confirmed this interaction when we restricted this analysis to people with vitamin D deficiency $(p=0.048)$ and asthma/COPD $(p=0.0005)$.

Correlations between changes in observed $25(\mathrm{OH}) \mathrm{D}$ concentration and changes in lung function measures are shown in supplementary Table S4. All FEV1 and FEV1/FVC correlations were in the positive direction. Among ever-smokers and their subgroups, $25(\mathrm{OH}) \mathrm{D}$ change was positively correlated ( $r=0.17$ to 0.34 ) with change in FEV1, which mirrors the FEV1 increases in these samples shown in Table 2. 
Table 2. Forced expiratory volume in $1 \mathrm{~s}(\mathrm{~mL})$ at baseline and follow-up (adjusted for age, sex, ethnicity and height) by treatment group.

\begin{tabular}{|c|c|c|c|c|c|c|c|c|}
\hline \multirow{3}{*}{ Sample } & \multicolumn{2}{|c|}{$n$} & \multicolumn{4}{|c|}{ Mean (Standard Deviation) } & \multirow{2}{*}{\multicolumn{2}{|c|}{$\begin{array}{l}\text { Change from Baseline, } \\
\text { Vitamin D Minus Placebo }\end{array}$}} \\
\hline & \multirow{2}{*}{$\begin{array}{l}\text { Vitamin D } \\
\text { Group }\end{array}$} & \multirow{2}{*}{$\begin{array}{l}\text { Placebo } \\
\text { Group }\end{array}$} & \multicolumn{2}{|c|}{ Vitamin D Group } & \multicolumn{2}{|c|}{ Placebo Group } & & \\
\hline & & & Baseline & Follow-Up & Baseline & Follow-Up & Mean $(95 \% \mathrm{CI})$ & $p$-Value \\
\hline Total & 226 & 216 & $2242(684)$ & $2313(687)$ & $2370(754)$ & 2325 (737) & $16(-19,51)$ & 0.38 \\
\hline Vitamin D-deficient ${ }^{1}$ & 61 & 68 & $2363(597)$ & $2363(620)$ & $2201(777)$ & $2162(774)$ & $39(-28,107)$ & 0.25 \\
\hline Asthma/COPD & 54 & 59 & $1869(600)$ & $1861(623)$ & $1951(735)$ & $1903(691)$ & $40(-33,112)$ & 0.28 \\
\hline Vitamin D-deficient ${ }^{1}+$ asthma/COPD & 16 & 27 & $2023(563)$ & $2079(574)$ & $1914(896)$ & $1861(844)$ & $109(-15,233)$ & 0.08 \\
\hline Ever-smoker & 104 & 113 & $2241(725)$ & $2232(750)$ & $2262(733)$ & $2197(693)$ & $57(4,109)$ & 0.03 \\
\hline Ever-smoker + vitamin D-deficient ${ }^{1}$ & 26 & 28 & $2348(641)$ & $2378(781)$ & $1912(616)$ & $1821(514)$ & $122(8,236)$ & 0.04 \\
\hline Ever-smoker + asthma/COPD & 25 & 35 & $1538(532)$ & $1632(565)$ & $1775(657)$ & $1709(582)$ & $160(53,268)$ & 0.004 \\
\hline
\end{tabular}

Table 3. Forced vital capacity $(\mathrm{mL})$ at baseline and follow-up (adjusted for age, sex, ethnicity and height) by treatment group.

\begin{tabular}{|c|c|c|c|c|c|c|c|c|}
\hline \multirow{3}{*}{ Sample } & \multicolumn{2}{|c|}{$n$} & \multicolumn{4}{|c|}{ Mean (Standard Deviation) } & \multirow{2}{*}{\multicolumn{2}{|c|}{$\begin{array}{l}\text { Change from Baseline, } \\
\text { Vitamin D Minus Placebo }\end{array}$}} \\
\hline & \multirow{2}{*}{$\begin{array}{l}\text { Vitamin D } \\
\text { Group }\end{array}$} & \multirow{2}{*}{$\begin{array}{l}\text { Placebo } \\
\text { Group }\end{array}$} & \multicolumn{2}{|c|}{ Vitamin D Group } & \multicolumn{2}{|c|}{ Placebo Group } & & \\
\hline & & & Baseline & Follow-UP & Baseline & Follow-Up & Mean $(95 \% \mathrm{CI})$ & $p$-Value \\
\hline Total & 226 & 216 & $3078(858)$ & $3060(861)$ & $3107(945)$ & $3093(910)$ & $-5(-49,39)$ & 0.83 \\
\hline Vitamin D-deficient ${ }^{1}$ & 61 & 68 & $3098(774)$ & $3085(783)$ & $2961(992)$ & $2941(949)$ & $7(-82,95)$ & 0.88 \\
\hline Asthma/COPD & 54 & 59 & $2885(833)$ & $2863(891)$ & $2889(976)$ & $2868(918)$ & $0(-96,96)$ & 0.99 \\
\hline Vitamin D-deficient ${ }^{1}+$ asthma/COPD & 16 & 27 & $2917(757)$ & $2967(770)$ & $2836(1172)$ & $2817(1110)$ & $69(-109,246)$ & 0.44 \\
\hline Ever-smoker & 104 & 113 & $2777(846)$ & $2979(882)$ & $3015(901)$ & $2976(840)$ & $42(-19,102)$ & 0.17 \\
\hline Ever-smoker + asthma/COPD & 25 & 35 & $2423(718)$ & $2486(639)$ & $2621(840)$ & $2598(770)$ & $86(-52,225)$ & 0.22 \\
\hline
\end{tabular}

${ }^{1}$ Baseline deseasonalized $25(\mathrm{OH}) \mathrm{D}<50 \mathrm{nmol} / \mathrm{L}$. 
Table 4. FEV1/FVC (\%) at baseline and follow-up (adjusted for age, sex, ethnicity and height) by treatment group.

\begin{tabular}{|c|c|c|c|c|c|c|c|c|}
\hline \multirow{3}{*}{ Sample } & \multicolumn{2}{|c|}{$n$} & \multicolumn{4}{|c|}{ Mean (Standard Deviation) } & \multirow{2}{*}{\multicolumn{2}{|c|}{$\begin{array}{l}\text { Change from Baseline, } \\
\text { Vitamin D Minus Placebo }\end{array}$}} \\
\hline & \multirow{2}{*}{$\begin{array}{l}\text { Vitamin D } \\
\text { Group }\end{array}$} & \multirow{2}{*}{$\begin{array}{l}\text { Placebo } \\
\text { Group }\end{array}$} & \multicolumn{2}{|c|}{ Vitamin D Group } & \multicolumn{2}{|c|}{ Placebo Group } & & \\
\hline & & & Baseline & Follow-UP & Baseline & Follow-Up & Mean $(95 \% \mathrm{CI})$ & $p$-Value \\
\hline Total & 226 & 216 & $76.4(7.7)$ & $76.0(7.6)$ & $76.6(7.4)$ & $75.4(7.0)$ & $0.7(-0.1,1.5)$ & 0.07 \\
\hline Vitamin D-deficient $^{1}$ & 61 & 68 & $76.6(6.5)$ & $76.8(7.0)$ & $74.3(8.6)$ & $73.4(8.0)$ & $1.2(-0.5,2.9)$ & 0.16 \\
\hline Asthma/COPD & 54 & 59 & $65.9(8.6)$ & $66.1(9.4)$ & $68.0(8.6)$ & $66.8(8.2)$ & $1.4(-0.2,3.0)$ & 0.08 \\
\hline Vitamin D-deficient ${ }^{1}+$ asthma/COPD & 16 & 27 & $69.7(9.4)$ & $70.2(9.8)$ & $67.3(9.9)$ & $66.0(8.0)$ & $1.9(-0.8,4.6)$ & 0.16 \\
\hline Ever-smoker & 104 & 113 & $75.2(7.8)$ & $75.0(7.7)$ & $75.3(8.1)$ & $74.0(7.7)$ & $1.1(0.0,2.5)$ & 0.05 \\
\hline Ever-smoker + vitamin D-deficient ${ }^{1}$ & 26 & 28 & $77.6(6.0)$ & $77.4(6.6)$ & $72.6(11.0)$ & $71.5(8.8)$ & $0.9(-1.4,3.2)$ & 0.42 \\
\hline Ever-smoker + asthma/COPD & 25 & 35 & $63.2(8.2)$ & $64.5(10.5)$ & $66.5(9.6)$ & $64.8(8.8)$ & $3.0(0.7,5.4)$ & 0.01 \\
\hline
\end{tabular}

FEV1 $=$ forced expiratory flow in $1 \mathrm{~s} ; \mathrm{FVC}=$ forced vital capacity. ${ }^{1}$ Baseline deseasonalized $25(\mathrm{OH}) \mathrm{D}<50 \mathrm{nmol} / \mathrm{L}$. 


\section{Discussion}

This randomized, double-blinded, placebo-controlled trial showed that monthly, high-dose vitamin D supplementation for just over 1 year did not affect lung function in the total sample, nor in subgroups defined by either vitamin D deficiency $(<50 \mathrm{nmol} / \mathrm{L})$ or having asthma/COPD. However, vitamin D supplementation did result in larger, statistically significant increases in FEV1 and FEV1 $z$-score among ever-smokers, especially those with vitamin D deficiency (FEV1 only) or asthma/COPD.

To our knowledge, this is the first study to show that vitamin D supplementation (compared to placebo) increases FEV1 and FEV1 z-score in ever-smokers. The restriction of this effect to ever-smokers only is consistent with observational research, which has shown stronger $25(\mathrm{OH}) \mathrm{D}$-lung function associations among smokers [1,17-19] and a stronger smoking-FEV1 relationship in vitamin D-deficient people [2]. Taken together, these findings suggest that vitamin D supplementation may mitigate smoking-associated lung function damage, although smoking avoidance and cessation remain paramount for preserving lung health.

Smoking decreases the production of 1,25-dihydroxyvitamin D in lung epithelial cells [29] and may affect expression levels of the vitamin D receptor [30]. Smoking-related lung destruction is partly mediated through inflammation, oxidative stress, and increased proteases [31,32], and these pathophysiological changes may persist even after smoking cessation [33]. However, vitamin D could mitigate these processes [34-36]. Further, there is increased activity of these processes in asthma [37] and COPD [31]. Collectively, these observations could explain our finding that vitamin D effects were limited to ever-smokers and were the largest in ever-smokers with asthma/COPD.

The effects of vitamin D among all asthma/COPD participants were non-significant (although in the positive direction), which concurs with some prior RCTs of patients with asthma $[9,10]$ or COPD $[4,5]$. We build on these past trials both by showing that the effects on asthma/COPD participants were stronger in ever-smokers (Tables 2 and 3 ) and because only one of these studies used the same dosing regimen we administered (monthly $\geq 100,000$ IU dosing for $\geq 1$ year) [5]. That study differed from ours in that it comprised largely men (80\%) with both mostly severe or very severe COPD and a history of recent exacerbations [5]; in contrast, our COPD cases were primarily mild or moderate, and were combined with predominantly well-controlled asthma cases.

The intervention effect for FEV1 as a percentage of the average lung function parameter value in the vitamin D group (both in Table 2) was modest (3\%) among all ever-smokers ( $57 \mathrm{~mL}$ as a percentage of $2241 \mathrm{~mL})$, larger $(5 \%)$ among vitamin D-deficient ever-smokers (122 $\mathrm{mL}$ as a percentage of $2348 \mathrm{~mL})$, and sizeable (10\%) among asthma/COPD ever-smokers (160 mL as a percentage of $1538 \mathrm{~mL})$. A change in FEV1 of at least $100 \mathrm{~mL}$ is considered to be clinically relevant $[38,39]$, suggesting that the net vitamin D effects on FEV1 among vitamin D-deficient ever-smokers (122 mL) and asthma/COPD ever-smokers $(160 \mathrm{~mL})$ in our study (Table 2$)$ represent, by definition, clinically meaningful improvements. Our FEV1 $z$-score results, which account for spirometric influences of demographics and height using a different statistical approach, provide further support of a benefit, with net vitamin D effects of 0.13 among all ever-smokers and 0.35 among ever-smokers with asthma/COPD (Table S1). Because there is a paucity of information on the size of the association between FEV1 $z$-scores and health outcomes $[40,41]$, more such research is required to quantify the clinical impact of these $z$-score results. As for FEV1/FVC, the effects on this parameter were meaningful: given that FEV1/FVC declines by $\sim 0.2 \%$ per year [26], the net vitamin D effects (increases) in FEV1/FVC of 1.1\% among all ever-smokers and 3.0\% among ever-smokers with asthma/COPD (Table 4) would correspond to changes that typically occur over 5.5 years and 15 years, respectively. Finally, as vitamin D effects on FEV1 were markedly more positive when analyses in asthma/COPD or vitamin D-deficient participants were restricted to ever-smokers than when they were not, this suggests that future RCTs of asthma, COPD or vitamin D-deficient people should carry out subgroup analyses among smokers to capture a potential difference in treatment effects.

Our study sample was population-based, as the vast majority of New Zealand residents (94\%) are registered with family practices [42]. This augments the external validity of our findings. Regarding 
limitations, the missingness of the intention-to-treat sample (Figure 1) renders our study findings prone to selection bias. However, as mentioned, this missingness did not differ across the treatment groups, and did not predict baseline lung function. The data analyst was not blinded to the treatment group, although we did include pre-specified analyses in our statistical analysis plan (mentioned above). The equations used to calculate our z-score results [26] may have limited applicability to our Maori and Pacific participants, as these ethnic groups were not included in the data that these $z$-scores are based on. A longer follow-up period may have allowed us to better evaluate the long-term efficacy of the intervention. Although our total sample size was large, relative to previous RCTs of vitamin D and lung function [3-10], our statistical power was limited (particularly for the subgroup analyses), which may explain why at least some treatment effects were not statistically significant. Finally, the multiplicity of statistical tests we performed raises the possibility that at least some of our significant findings may have been due to chance. However, we observed positive dose-response relationships between change in $25(\mathrm{OH}) \mathrm{D}$ and change in lung function (Table S4), which supports a true effect (biological gradient). Further support includes the fact that, as reported, the FEV1 and FEV1 $z$-score treatment effects were consistent with observational research, biologically plausible, and were all unidirectional (across samples; Table 2). Also, if study conclusions are based on the primary outcome (FEV1) results only, far fewer comparisons are involved.

Our analyses were based on subsamples of an RCT (Figure 1). Although a limitation, we do not expect there to be marked, systematic differences in baseline participant characteristics, for the following reasons: Firstly, the selection of our total analysis sample from the main ViDA study was random. Second, as everybody was randomized in the same way, the selection of subgroups from the total sample should not differ across treatment groups. Third, since the analyses controlled for age, sex, ethnicity and height, effects of any imbalances in these demographic variables would have been minimized. Fourth, stratifying the study randomization by our subgroup variables (vitamin $D$ deficiency, asthma/COPD and ever-smokers) could have reduced any baseline imbalances within these subgroups [43]. Although we did not do this, this effect would have been partially captured, as we stratified randomization by age and ethnicity, which are associated with these subgroup variables $[44,45]$. Further, some have proposed that stratification of randomization is not required for pre-specified subgroup analyses (such as ours) [46].

In summary, monthly high-dose vitamin D supplementation over an average of 1.1 years, which increased serum $25(\mathrm{OH}) \mathrm{D}$ concentration by $>50 \mathrm{nmol} / \mathrm{L}$ with respect to placebo, did not improve lung function in the overall study population. In subgroup analyses, we found that vitamin $\mathrm{D}$ supplementation improved lung function (FEV1 and FEV z-score) in ever-smokers, particularly those with vitamin D deficiency (FEV1 only) or asthma/COPD. We encourage similar RCTs in smokers to assess the efficacy of different dosing regimens (e.g., daily or weekly supplementation). Additional RCTs are needed to investigate whether the observed beneficial effects translate into improvements in lung function-related health, such as improved asthma/COPD control.

Supplementary Materials: The following are available online at www.mdpi.com/2072-6643/9/12/1353/s1, Table S1: FEV1 $z$-scores at baseline and follow-up (adjusted for age, sex, ethnicity and height) by treatment group; Table S2: FVC $z$-scores at baseline and follow-up (adjusted for age, sex, ethnicity and height) by treatment group; Table S3: FEV1/FVC z-scores at baseline and follow-up (adjusted for age, sex, ethnicity and height) by treatment group; Table S4: Correlations of changes in observed $25(\mathrm{OH}) \mathrm{D}$ concentration with changes in lung function measures.

Acknowledgments: We thank the participants and the ViDA study staff. The Health Research Council of New Zealand (HRC) and Accident Compensation Corporation of New Zealand funded this study. HRC supported J.D.S. with a postdoctoral fellowship.

Author Contributions: C.A.C.J., C.M.M.L., L.T. and K.-T.K. and R.S. designed the research. R.S. supervised the study. D.W., C.M.M.L., K.-T.K. and R.S. provided administrative, technical or material support. J.D.S., C.A.C.J., D.W., C.M.M.L., L.T. and R.S. contributed to data acquisition, management or interpretation. J.D.S. analysed data and drafted the manuscript. J.D.S. had primary responsibility for final content. All authors critically reviewed the manuscript, and read and approved the final version.

Conflicts of Interest: The authors declare no conflict of interest. 


\section{References}

1. Black, P.N.; Scragg, R. Relationship between serum 25-hydroxyvitamin D and pulmonary function in the Third National Health and Nutrition Examination Survey. Chest 2005, 128, 3792-3798. [CrossRef] [PubMed]

2. Lange, N.E.; Sparrow, D.; Vokonas, P.; Litonjua, A.A. Vitamin D deficiency, smoking, and lung function in the normative aging study. Am. J. Respir. Crit. Care Med. 2012, 186, 616-621. [CrossRef] [PubMed]

3. Price, O.J.; Hull, J.H.; Howatson, G.; Robson-Ansley, P.; Ansley, L. Vitamin D and omega-3 polyunsaturated fatty acid supplementation in athletes with exercise-induced bronchoconstriction: A pilot study. Expert Rev. Respir. Med. 2015, 9, 369-378. [CrossRef] [PubMed]

4. Moosavi, S.A.J.; Shoushtari, M.H. The effects of vitamin D supplementation on pulmonary function of chronic obstructive pulmonary disease patients, before and after clinical trial. Diseases 2015, 3, $253-259$. [CrossRef] [PubMed]

5. Lehouck, A.; Mathieu, C.; Carremans, C.; Baeke, F.; Verhaegen, J.; van Eldere, J.; Decallonne, B.; Bouillon, R.; Decramer, M.; Janssens, W. High doses of vitamin D to reduce exacerbations in chronic obstructive pulmonary disease: A randomized trial. Ann. Intern. Med. 2012, 156, 105-120. [CrossRef] [PubMed]

6. Castro, M.; King, T.S.; Kunselman, S.J.; Cabana, M.D.; Denlinger, L.; Holguin, F.; Kazani, S.D.; Moore, W.C.; Moy, J.; Sorkness, C.A.; et al. Effect of vitamin D3 on asthma treatment failures in adults with symptomatic asthma and lower vitamin D levels: The VIDA randomized clinical trial. JAMA 2014, 311, $2083-2091$. [CrossRef] [PubMed]

7. Zendedel, A.; Gholami, M.; Anbari, K.; Ghanadi, K.; Bachari, E.C.; Azargon, A. Effects of vitamin D intake on FEV1 and COPD exacerbation: A randomized clinical trial study. Glob. J. Health Sci. 2015, 7, $243-248$. [CrossRef] [PubMed]

8. Arshi, S.; Fallahpour, M.; Nabavi, M.; Bemanian, M.H.; Javad-Mousavi, S.A.; Nojomi, M.; Esmaeilzadeh, H.; Molatefi, R.; Rekabi, M.; Jalali, F.; et al. The effects of vitamin D supplementation on airway functions in mild to moderate persistent asthma. Ann. Allergy Asthma Immunol. 2014, 113, 404-409. [CrossRef] [PubMed]

9. De Groot, J.C.; van Roon, E.N.H.; Storm, H.; Veeger, N.J.G.M.; Zwinderman, A.H.; Hiemstra, P.S.; Bel, E.H.D.; Ten Brinke, A. Vitamin D reduces eosinophilic airway inflammation in nonatopic asthma. J. Allergy Clin. Immunol. 2015, 135, 670-675. [CrossRef] [PubMed]

10. Martineau, A.R.; MacLaughlin, B.D.; Hooper, R.L.; Barnes, N.C.; Jolliffe, D.A.; Greiller, C.L.; Kilpin, K.; McLaughlin, D.; Fletcher, G.; Mein, C.A.; et al. Double-blind randomised placebo-controlled trial of bolus-dose vitamin D3 supplementation in adults with asthma (ViDiAs). Thorax 2015, 70, 451-457. [CrossRef] [PubMed]

11. Ali, A.M.; Selim, S.; Abbassi, M.M.; Sabry, N.A. Effect of alfacalcidol on the pulmonary function of adult asthmatic patients: A randomized trial. Ann. Allergy Asthma Immunol. 2017, 118, 557-563. [CrossRef] [PubMed]

12. Nageswari, A.D.; Rajanandh, M.G.; Priyanka, R.K.; Rajasekhar, P. Effect of vitamin D3 on mild to moderate persistent asthmatic patients: A randomized controlled pilot study. Perspect. Clin. Res. 2014, 5, 167-171. [CrossRef] [PubMed]

13. Camargo, C.A., Jr.; Budinger, G.R.S.; Escobar, G.J.; Hansel, N.N.; Hanson, C.K.; Huffnagle, G.B.; Buist, A.S. Promotion of lung health: NHLBI workshop on the primary prevention of chronic lung diseases. Ann. Am. Thorac. Soc. 2014, 11, S125-S138. [CrossRef] [PubMed]

14. Zittermann, A.; Iodice, S.; Pilz, S.; Grant, W.B.; Bagnardi, V.; Gandini, S. Vitamin D deficiency and mortality risk in the general population: A meta-analysis of prospective cohort studies. Am. J. Clin. Nutr. 2012, 95, 91-100. [CrossRef] [PubMed]

15. Wang, L.; Song, Y.; Manson, J.E.; Pilz, S.; März, W.; Michaëlsson, K.; Lundqvist, A.; Jassal, S.K.; Barrett-Connor, E.; Zhang, C.; et al. Circulating 25-Hydroxy-Vitamin D and risk of cardiovascular disease: A meta-analysis of prospective studies. Circ. Cardiovasc. Qual. Outcomes 2012, 5, 819-829. [CrossRef] [PubMed]

16. Martineau, A.R.; Jolliffe, D.A.; Hooper, R.L.; Greenberg, L.; Aloia, J.F.; Bergman, P.; Dubnov-Raz, G.; Esposito, S.; Ganmaa, D.; Ginde, A.A.; et al. Vitamin D supplementation to prevent acute respiratory tract infections: Systematic review and meta-analysis of individual participant data. BMJ 2017, 356. [CrossRef] [PubMed] 
17. Larose, T.L.; Brumpton, B.M.; Langhammer, A.; Camargo, C.A., Jr.; Chen, Y.; Romundstad, P.; Mai, X.M. Serum 25-hydroxyvitamin D level, smoking and lung function in adults: The HUNT Study. Eur. Respir. J. 2015, 46, 355-363. [CrossRef] [PubMed]

18. Afzal, S.; Lange, P.; Bojesen, S.E.; Freiberg, J.J.; Nordestgaard, B.G. Plasma 25-hydroxyvitamin D, lung function and risk of chronic obstructive pulmonary disease. Thorax 2014, 69, 24-31. [CrossRef] [PubMed]

19. Xu, J.; Bartz, T.M.; Chittoor, G.; Eiriksdottir, G.; Manichaikul, A.W.; Sun, F.; Terzikhan, N.; Zhou, X.; Booth, S.L.; Brusselle, G.G.; et al. Large meta-analysis provides evidence for an association of serum vitamin D with pulmonary function. bioRxiv 2017. [CrossRef]

20. Scragg, R.; Waayer, D.; Stewart, A.W.; Lawes, C.M.M.; Toop, L.; Murphy, J.; Khaw, K.T.; Camargo, C.A., Jr. The Vitamin D Assessment (ViDA) Study: Design of a randomized controlled trial of vitamin D supplementation for the prevention of cardiovascular disease, acute respiratory infection, falls and non-vertebral fractures. J. Steroid Biochem. Mol. Biol. 2016, 164, 318-325. [CrossRef] [PubMed]

21. Moher, D.; Hopewell, S.; Schulz, K.F.; Montori, V.; Gøtzsche, P.C.; Devereaux, P.J.; Elbourne, D.; Egger, M.; Altman, D.G. CONSORT 2010 explanation and elaboration: Updated guidelines for reporting parallel group randomised trials. BMJ 2010, 340. [CrossRef] [PubMed]

22. Schatz, M.; Sorkness, C.A.; Li, J.T.; Marcus, P.; Murray, J.J.; Nathan, R.A.; Kosinski, M.; Pendergraft, T.B.; Jhingran, P. Asthma Control Test: Reliability, validity, and responsiveness in patients not previously followed by asthma specialists. J. Allergy Clin. Immunol. 2006, 117, 549-556. [CrossRef] [PubMed]

23. Holt, S.; Sheahan, D.; Mackey, B.; Jacobsen, C. Use of Asthma Control Test (ACT) affects New Zealand primary care doctors' perception of asthma control. N. Z. Med. J. 2011, 124, 99-101. [PubMed]

24. Miller, M.R.; Hankinson, J.; Brusasco, V.; Burgos, F.; Casaburi, R.; Coates, A.; Crapo, R.; Enright, P.; van der Grinten, C.P.M.; Gustafsson, P.; et al. Standardisation of spirometry. Eur. Respir. J. 2005, 26, 319-338. [CrossRef] [PubMed]

25. Global Initiative for Chronic Obstructive Lung Disease. Global Strategy for the Diagnosis, Management, and Prevention of Chronic Obstructive (2017 Report). Available online: http:/ /goldcopd.org/gold-2017-globalstrategy-diagnosis-management-prevention-copd/ (accessed on 2 March 2017).

26. Quanjer, P.H.; Stanojevic, S.; Cole, T.J.; Baur, X.; Hall, G.L.; Culver, B.H.; Enright, P.L.; Hankinson, J.L.; Ip, M.S.M.; Zheng, J.; et al. Multi-ethnic reference values for spirometry for the 3-95-yr age range: The global lung function 2012 equations. Eur. Respir. J. 2012, 40, 1324-1343. [CrossRef] [PubMed]

27. Sachs, M.C.; Shoben, A.; Levin, G.P.; Robinson-Cohen, C.; Hoofnagle, A.N.; Swords-Jenny, N.; Ix, J.H.; Budoff, M.; Lutsey, P.L.; Siscovick, D.S.; et al. Estimating mean annual 25-hydroxyvitamin D concentrations from single measurements: The Multi-Ethnic Study of Atherosclerosis. Am. J. Clin. Nutr. 2013, 97, 1243-1251. [CrossRef] [PubMed]

28. Rothman, K.J. No adjustments are needed for multiple comparisons. Epidemiology 1990, 1, 43-46. [CrossRef] [PubMed]

29. Hansdottir, S.; Monick, M.M.; Lovan, N.; Powers, L.S.; Hunninghake, G.W. Smoking disrupts vitamin D metabolism in the lungs. Am. J. Respir. Crit. Care Med. 2010, 181. [CrossRef]

30. Haley, K.J.; Manoli, S.E.; Tantisira, K.G.; Litonjua, A.A.; Nguyen, P.; Kobzik, L.; Weiss, S.T. Maternal smoking causes abnormal expression of the vitamin D receptor. Am. J. Respir. Crit. Care Med. 2009, 179. [CrossRef]

31. Fischer, B.M.; Pavlisko, E.; Voynow, J.A. Pathogenic triad in COPD: Oxidative stress, protease-antiprotease imbalance, and inflammation. Int. J. Chronic Obstruct. Pulm. Dis. 2011, 6, 413-421. [CrossRef] [PubMed]

32. Shapiro, S.D. Proteolysis in the lung. Eur. Respir. J. 2003, 22, 30s-32s. [CrossRef]

33. Mortaz, E.; Masjedi, M.R.; Rahman, I. Outcome of smoking cessation on airway remodeling and pulmonary inflammation in COPD patients. Tanaffos 2011, 10, 7-11. [PubMed]

34. Baeke, F.; Takiishi, T.; Korf, H.; Gysemans, C.; Mathieu, C. Vitamin D: Modulator of the immune system. Curr. Opin. Pharmacol. 2010, 10, 482-496. [CrossRef] [PubMed]

35. Kim, S.H.; Baek, M.S.; Yoon, D.S.; Park, J.S.; Yoon, B.W.; Oh, B.S.; Park, J.; Kim, H.J. Vitamin D inhibits expression and activity of matrix metalloproteinase in human lung fibroblasts (HFL-1) cells. Tuberc. Respir. Dis. 2014, 77, 73-80. [CrossRef] [PubMed]

36. Ke, C.Y.; Yang, F.L.; Wu, W.T.; Chung, C.H.; Lee, R.P.; Yang, W.T.; Subeq, Y.M.; Liao, K.W. Vitamin D3 reduces tissue damage and oxidative stress caused by exhaustive exercise. Int. J. Med. Sci. 2016, 13, 147-153. [CrossRef] [PubMed] 
37. Mak, J.C.W.; Ho, S.P.; Ho, A.S.S.; Law, B.K.W.; Cheung, A.H.K.; Ho, J.C.M.; Ip, M.S.M.; Chan-Yeung, M.M.W. Sustained elevation of systemic oxidative stress and inflammation in exacerbation and remission of asthma. ISRN Allergy 2013, 2013. [CrossRef] [PubMed]

38. Donohue, J.F. Minimal clinically important differences in COPD lung function. COPD 2005, 2, 111-124. [CrossRef] [PubMed]

39. Jones, P.W.; Beeh, K.M.; Chapman, K.R.; Decramer, M.; Mahler, D.A.; Wedzicha, J.A. Minimal clinically important differences in pharmacological trials. Am. J. Respir. Crit. Care Med. 2014, 189, 250-255. [CrossRef] [PubMed]

40. Vaz Fragoso, C.A.; Concato, J.; McAvay, G.; Klar Yaggi, H.; van Ness, P.H.; Gill, T.M. Staging the severity of chronic obstructive pulmonary disease in older persons based on spirometric Z-scores. J. Am. Geriatr. Soc. 2011, 59, 1847-1854. [CrossRef] [PubMed]

41. Lee, S.W.; Kim, H.K.; Baek, S.; Jung, J.-Y.; Kim, Y.S. Development of a spirometry T-score in the general population. Int. J. Chron. Obstruct. Pulm. Dis. 2016, 11, 369-379.

42. Ministry of Health New Zealand. Enrollment in a Primary Health Organisation. Available online: http:/ / www.health.govt.nz/our-work/primary-health-care/about-primary-health-organisations / enrolment-primary-health-organisation (accessed on 17 November 2017).

43. Dijkman, B.; Kooistra, B.; Bhandari, M.; Archibald, S.; Baillie, F.; Cadeddu, M.; Cinà, C.; Farrokhyar, F.; Goldsmith, C.H.; Haines, T.; et al. How to work with a subgroup analysis. Can. J. Surg. 2009, 52, 515-522. [PubMed]

44. Nessvi, S.; Johansson, L.; Jopson, J.; Stewart, A.; Reeder, A.; McKenzie, R.; Scragg, R.K. Association of 25-hydroxyvitamin D3 levels in adult New Zealanders with ethnicity, skin color and self-reported skin sensitivity to sun exposure. Photochem. Photobiol. 2011, 87, 1173-1178. [CrossRef] [PubMed]

45. Milne, R.J.; Beasley, R. Hospital admissions for chronic obstructive pulmonary disease in New Zealand. N. Z. Med. J. 2015, 128, 23-35. [PubMed]

46. Kaiser, L.D. Stratification of randomization is not required for a pre-specified subgroup analysis. Pharm. Stat. 2013, 12, 43-47. [CrossRef] [PubMed] 